University of Nebraska - Lincoln

DigitalCommons@University of Nebraska - Lincoln

2004

\title{
Farm Fatalities to Youth 1995-2000: A Comparison by Age Groups
}

\author{
Michael Goldcamp \\ Centers for Disease Control and Prevention, National Institute for Occupational Safety and Health, \\ Morgantown, WV, USA \\ Kitty J. Hendricks \\ Centers for Disease Control and Prevention, National Institute for Occupational Safety and Health, \\ Morgantown, WV, USA \\ John R. Myers \\ Centers for Disease Control and Prevention, National Institute for Occupational Safety and Health, \\ Morgantown, WV, USA
}

Follow this and additional works at: https://digitalcommons.unl.edu/publichealthresources

Part of the Public Health Commons

Goldcamp, Michael; Hendricks, Kitty J.; and Myers, John R., "Farm Fatalities to Youth 1995-2000: A Comparison by Age Groups" (2004). Public Health Resources. 18.

https://digitalcommons.unl.edu/publichealthresources/18

This Article is brought to you for free and open access by the Public Health Resources at DigitalCommons@University of Nebraska - Lincoln. It has been accepted for inclusion in Public Health Resources by an authorized administrator of DigitalCommons@University of Nebraska - Lincoln. 


\title{
Farm fatalities to youth 1995-2000: A comparison by age groups
}

\author{
Michael Goldcamp*, Kitty J. Hendricks, John R. Myers \\ Centers for Disease Control and Prevention, National Institute for Occupational Safety and Health, Morgantown, WV, USA
}

Received 15 July 2003; received in revised form 23 October 2003; accepted 21 November 2003

Available online 7 May 2004

\begin{abstract}
Problem: Although a myriad of research illustrates the safety issues related to farm fatalities in youth populations, very little empirical evidence exists that includes work and non-work related farm fatalities to all youths under 20 years of age at the national level. Methods: This research will use death certificate data for the six years from 1995 to 2000 that were collected by NIOSH from all 50 state vital statistics registries. Demographic data from the 1998 CAIS were used in rate calculations. In addition to providing annual fatality rates and descriptions of the general causes of death, this research will examine the variation between age groups. Results: Analysis of 695 total farmrelated youth fatalities shows an average annual fatality rate of 9.3 fatalities per 100,000 youths. Males account for $80 \%$ of these fatalities. The most prevalent causes of death are: machinery $(25 \%)$, motor vehicle $(17 \%)$, drowning $(16 \%)$, suicide $(8 \%)$ and homicide $(6 \%)$. Of all youth fatalities occurring while at work, $45 \%$ are to youths less than 16 years of age. This same age group accounts for $71 \%$ of all non-work related fatalities. Summary: This research will provide farm families and researchers more detailed information on farm hazards that contribute to the deaths of youths. As these youths may encounter hazards while working or playing in their daily environment, identification and elimination of these hazards will increase overall safety on the farm. This research also indicates the need to include youths under 16 years of age in future comprehensive farm safety research.
\end{abstract}

\section{Problem}

According to estimates derived from the 1998 Childhood Agricultural Injury Survey (CAIS), approximately 1.9 million youths under 20 years of age live and work on farms in the United States (Myers \& Hendricks, 2001). Given the nature of work done on farms and the dual role of farms as a home and a workplace, these youths are continually exposed to many unique hazards (Rivara, 1997). According to Adekoya and Pratt (2001), there were 2,174 youths under 20 years of age fatally injured on farms between 1982 and 1996 , or an average of approximately 155 deaths annually. Although these researchers found that the annual number of deaths appears to be decreasing, the risks and hazards remain high. This indicates a continued need for research to identify the dangers that youths face on a daily basis so that effective prevention strategies can be implemented.

\footnotetext{
* Corresponding author. Tel.: +1-304-285-5951; fax: +1-304-2855774.

E-mail address: ehg8@cdc.gov (M. Goldcamp).
}

Although research exists that describes general farm injuries and fatalities to youths (Adekoya \& Pratt, 2001; Myers \& Adekoya, 2001; Rivara, 1997, 1985), most studies have a limited scope. Studies using databases, such as the National Traumatic Occupational Fatalities (NTOF; which is death certificate-based) and the multiple source Census of Fatal Occupational Injuries (CFOI) surveillance systems (Janicak, 2000; Castillo, Adekoya, \& Myers, 1999; Conroy \& Sciortino, 1997; Derstine, 1996), provide insightful information on occupational injuries, but do not address non-occupational deaths or include younger children. Other studies using state-specific vital records-based data systems provide specific local information, but do not allow for national estimates (Richardson, Loomis, Wolf, \& Gregory, 1997; Schulman, Evensen, Runyan, Cohen, \& Dunn, 1997; Tormoehlen, 1986; Field \& Tormoehlen, 1982).

In order to address fatal farm injuries to youths under 20 years of age, Adekoya and Pratt (2001) used National Center for Health Statistics (NCHS) mortality data. They found that approximately two-thirds of all farm fatalities occurred to youths under 15 years of age $(1,432$ of 2,174 
fatalities from 1982 to 1996). In addition, the leading causes of death for these youths were machinery, drowning, and animals. Adekoya and Pratt indicate a large number of fatalities in the under 15 age group, and some variation in the likely causes of injury. However, several limitations of their research are evident. First, their data do not allow for the distinction between occupational and non-occupational injuries. Second, the coding system used does not allow for inclusion of either transportation or intentional fatalities. Finally, fatalities that occurred within the farm home were not included. Therefore, their data may under-represent the number of youth fatalities on the farm.

Since youths are exposed to hazards both while working and living on the farm, it is important to include: (a) all nonoccupational fatalities to youths and (b) fatalities to youths less than 16 years of age. Most of the previously mentioned studies exclude at least one of these two components. The intent of this current research is to help fill in these gaps by re-examining the fatality experience of youths on U.S. farms through the use of death certificate data. In addition to examining fatality rates by cause of death, this research will examine the variation between age groups. In particular, a distinction will be made between youths 16 and over and youths under 16 years of age, and will include both occupational and non-occupational fatalities.

\section{Methods}

This research uses death certificate data collected by the National Institute for Occupational Safety and Health (NIOSH) through a special request of all 50 state vital statistics registries. Records satisfying the following criteria were requested: underlying, immediate, or contributing cause of death from an external factor (International Classification of Diseases. 9th Revision. E800-E999); age of the decedent is less than 20 years; and the indicated location of death is a farm. The results include information for 695 fatalities occurring in the years 1995 through 2000. For 1999 and 2000, data are missing for the following states: Delaware, Massachusetts, Michigan, Nebraska, New Jersey, New York, and Oregon. From 1995 to 1998, these states accounted for $8 \%$ (37) of the fatalities, or approximately nine fatalities annually. It must also be noted that no data are available for New York City, but it is unlikely that New York City incurs agriculture-related fatalities.

Information from these 695 death certificates was automated using double-blind data entry. This process involved two staff independently entering the data into a computerized database. These two complete data sets were then compared, with discrepancies resolved by an independent third party. An event was considered occupational if the "injury at work?" item was marked "yes." Because the hard copies of the death certificate information did not include cause of injury codes, NIOSH staff used the narrative information to code each fatality according to the International Classification of Dis- eases 9th Revision (ICD-9; World Health Organization, 1977) standards. In cases where the narrative information was missing or incomplete, ICD-9 codes for unknown were used. Descriptive statistics were then calculated to determine the frequency of each cause of death and the percentage of the overall number of fatalities accounted for within each cause of death. The narratives were also used to determine additional information about these deaths (e.g., whether a tractor was involved in a machinery-related death).

In order to calculate age-specific fatality rates, survey data obtained from the 1998 CAIS (Myers \& Hendricks, 2001) were used to determine the approximate annual population of individuals under 20 years of age living or working on U.S. farms. The CAIS, conducted for NIOSH by the National Agricultural Statistics Service (NASS) within the U.S. Department of Agriculture (USDA), collected data through a regionally stratified random sample of approximately 26,000 farms. Each selected farm, contacted via telephone, was asked to provide demographic information, including the number of children under 20 years of age living or working on the farm. The resulting estimated population was used to estimate the fatality rate, presented as an annual rate per 100,000 youths. The standard errors of the fatality rates were derived from the standard errors of the youths estimates from the 1998 CAIS. The calculation of the standard errors from the CAIS are provided in Myers and Hendricks (2001).

\section{Results}

\subsection{Demographics}

For the years 1995 to 2000, a total of 695 farm-related fatalities for youths under 20 years of age were identified. The annual distribution of these fatalities is shown in Fig. 1. Generally the demographic variation among these injuries follows trends common to previous findings. Males accounted for 554 (80\%) of these fatalities. As age increases, the ratio of male to female fatalities increases. In the $0-4$ age group, only $69 \%$ of the victims were male, while in the $16-$ 19 age group, $91 \%$ of the victims were male. Ninety-two percent of the fatalities studied were to white children. Five hundred seventy-two (82\%) of the fatalities occurred on the farm property, of which only 36 were within the farm house. The remaining 123 (18\%) were farm-related fatalities occurring off farm property. Over $40 \%$ of all fatalities occurred in the months June through August. Fig. 2 shows the temporal trend was similar for both children under 16 years of age and youths 16 to 19 years of age.

In terms of the victim's age, the distribution of fatalities indicates that the youngest and oldest youths were most likely to be involved in a fatal incident (Fig. 3). The highest annual fatality rate by age was for youths 16 to 19 years of age (10.4 annual fatalities per 100,000 youths). The fatality rate for youths under 10 years of age was very similar at 10.1 annual 


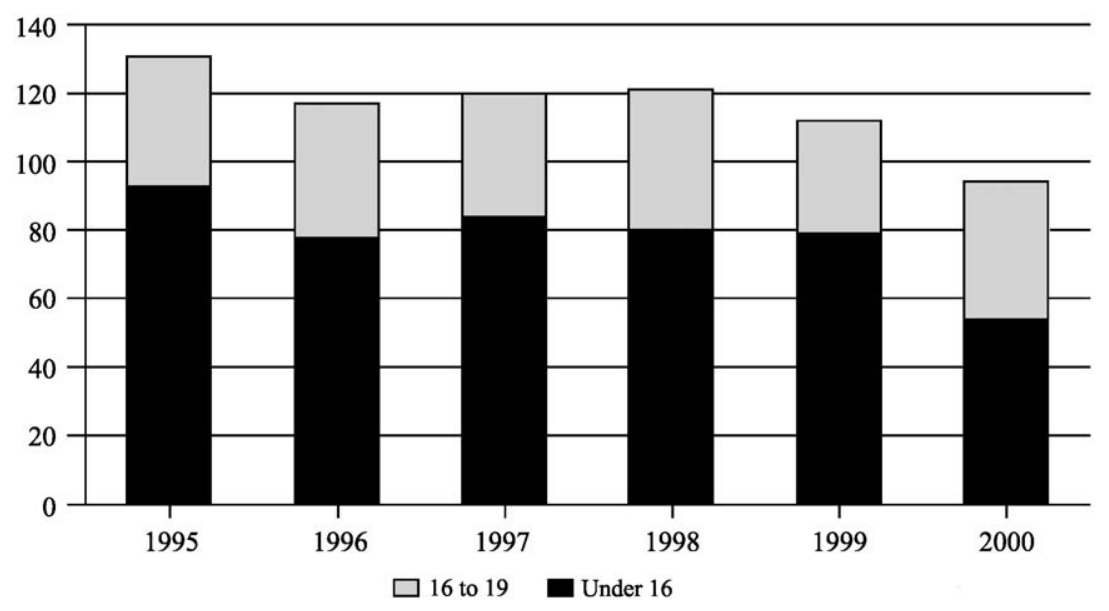

Fig. 1. Fatalities on U.S. Farms for Youth Under 20 Years of Age by Age Group: 1995-2000. Source: Death certificate data: years 1999 and 2000 exclude data from Delaware, Massachussetts, Michigan, Nebraska, New Jersey, New York, and Oregon; years 1995 through 2000 exclude New York City.

fatalities per 100,000 youths, while youths 10 to 15 years age had a fatality rate of 7.1 per 100,000 youths. A total of 469 fatalities occurred in children under 16 years of age $(8.7$ fatalities per 100,000). In general, U.S. farms appeared to be just as dangerous to younger children as to older youths.

With respect to the above rate calculations, the numerator did not include fatalities that occurred in non-reporting states. The population estimates, the denominator, however, did include the non-reporting states due to the nature of the CAIS data. Therefore, rates reported are considered a conservative estimate.

The vast majority of fatalities on farms $(569,82 \%)$ were deemed not to be due to the victim's work. Ninety-four fatalities $(14 \%)$ were identified as work-related on the death certificate. In the remaining 32 cases, the relation to work was unknown or missing. Of those 94 fatalities that were work-related, $42(45 \%)$ victims were younger than 16 years of age with $9(10 \%)$ being less than 10 years of age. Overall, these data indicate a relatively low number of work-related fatalities when compared to youths not working, with the majority of work-related victims being in the older age groups. However, it must be noted that determination of work-related agricultural injuries is difficult. Fatalities resulting from the work of others are generally not included, and youth fatalities occurring while the youth is performing unpaid work may be lost. For example, although the majority of the 61 tractor-related fatalities to youths under 16 years of age appear to be related to work being performed on the farm, only 11 were coded as work-related with regard to the decedent.

\subsection{Causes of Death}

As shown in Table 1, the most prevalent causes of farmrelated youth deaths according to ICD-9 classifications were machine-related $(171,25 \%$ of fatalities), motor vehicles $(121,17 \%)$, and drowning $(112,16 \%)$. This is consistent with known risk factors associated with farming (Adekoya \& Pratt, 2001; Myers \& Adekoya, 2001; Castillo et al., 1999). In terms of occupational injuries, of the 94 workrelated cases, $45(48 \%)$ cited that the cause of death was machinery-related. The next most common cause of death

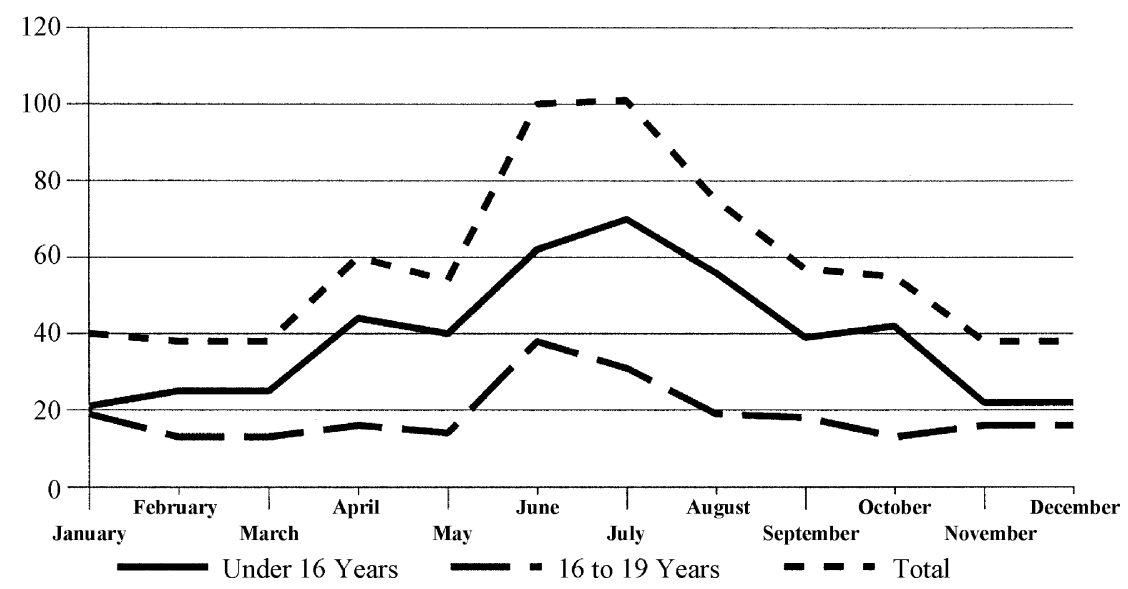

Fig. 2. Fatalities on U.S. Farms for Youth Under 20 Years of Age: 1995-2000. Source: Death certificate data: years 1999 and 2000 exclude data from Delaware, Massachussetts, Michigan, Nebraska, New Jersey, New York, and Oregon; years 1995 through 2000 exclude New York City. 


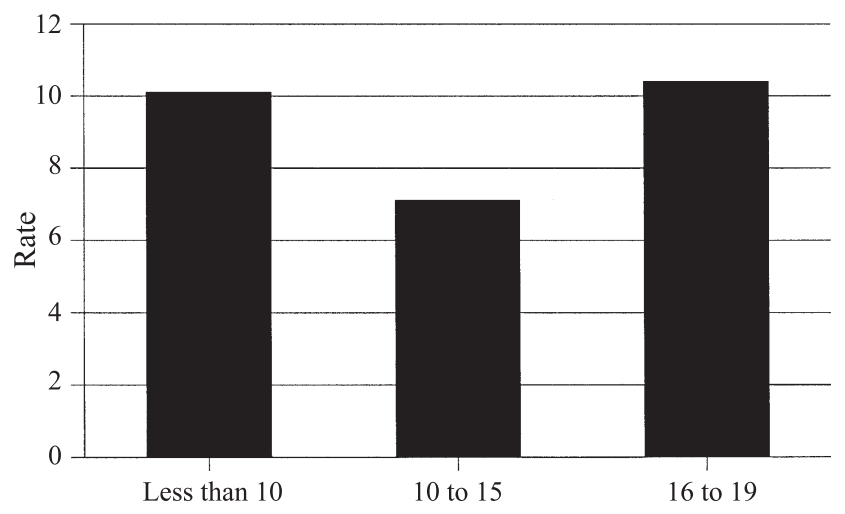

Fig. 3. Annual Fatality Rate* by Age Group for Youth Under 20 Years of Age on U.S. Farms. Source: Death certificate data and Chilhood Agricultural Injury Survey.

for work-related fatalities involve the decedent being struck by a falling object, accounting for 8 fatalities or $9 \%$ of all work-related cases. The remaining 41 work-related fatalities were fairly evenly distributed among the other causes of death.

For clarification of certain ICD-9 codes, it is important to note the predominant source of injury within specific categories. Explosions generally refer to gunshot wounds, of which many involve hunting activities. Machine-related events include incidents involving farm tractors, trailers pulled by tractors on the farm, and equipment. Many of these machine deaths involve injuries sustained from being crushed by farm tractors or other mobile equipment. Motor-vehicle fatalities include both on- and off-road incidents, including those that occur on the farm but may not be farm related.

Table 1

Cause of Death For youths under 20 years of age on U.S. farms, 19952000

\begin{tabular}{lrcll}
\hline Category & Deaths & Percent & Rate $^{\mathrm{a}}$ & Std. Err. \\
\hline Machine & 171 & 24.6 & 2.3 & 0.032 \\
Motor vehicle & 121 & 17.4 & 1.6 & 0.023 \\
Drowning & 112 & 16.1 & 1.5 & 0.021 \\
Suicide & 55 & 7.9 & 0.7 & 0.010 \\
Homicide & 38 & 5.5 & 0.5 & 0.007 \\
Suffocation & 30 & 4.3 & 0.4 & 0.006 \\
Animal & 30 & 4.3 & 0.4 & 0.006 \\
Explosion & 30 & 4.3 & 0.4 & 0.006 \\
Struck by falling object & 28 & 4.0 & 0.4 & 0.005 \\
Electrocution & 16 & 2.3 & 0.2 & 0.003 \\
Fall & 14 & 2.0 & 0.2 & 0.003 \\
Nature/environment & 11 & 1.6 & 0.2 & 0.002 \\
Poisoning & 9 & 1.3 & 0.1 & 0.002 \\
Air transport & 9 & 1.3 & 0.1 & 0.002 \\
Flying object/caught in & 6 & 0.9 & 0.1 & 0.001 \\
Fire & 6 & 0.9 & 0.1 & 0.001 \\
Unknown & 9 & 1.3 & $N / A$ & $N / A$ \\
Total & 695 & 100 & 9.3 & 0.129 \\
\hline Source Death & &
\end{tabular}

Source: Death certificate data: years 1999 and 2000 exclude data from Delaware, Massachusetts, Michigan, Nebraska, New Jersey, New York, and Oregon; years 1995-2000 exclude New York City.

${ }^{\text {a }}$ Rate refers to annual number of fatalities per 100,000 youths under 20 years of age.
It should also be noted that the homicide deaths in this study may include situations in which the victim had no relation to the farm prior to death. In addition, the homicides included in these data do not necessarily occur on farm property. If a body is discovered on a farm, the death certificate may indicate the farm as the location of death regardless of where the decedent was killed. The death certificate narratives do not include information useful in determining actual location of death.

To more accurately compare the causes of fatalities between age groups, we calculated annual fatality rates per 100,000 youths within each age group (Table 2). As stated previously, rates are considered conservative due to non-reporting in states for some of the study period. In general, children under 16 appeared more likely to die as a result of machines, motor vehicles, and animals than youths 16- to 19-years old. However, older youths were more likely to be the victim of all other reportable causes of death. The two highest annual fatality rates (per 100,000) for the 16 to 19 years age group are suicide (1.9 per 100,000) and drowning $(1.7$ per 100,000$)$ deaths. With regard to suicide, $14(25 \%)$ occurred to youths 11 to 15 years of age, while the remaining 41 fatalities are to youths 16 to 19 years of age. The two highest rates for the younger age group are machine-related $(2.5$ per 100,000$)$ and motor vehicle $(1.77$ per 100,000$)$ fatalities. Within the 0 to 15 years age group,

Table 2

Estimated Fatality Rates for Cause of Death by Age Group For youths under 20 years of age on U.S. farms, 1995-2000

\begin{tabular}{|c|c|c|c|c|c|c|}
\hline \multirow{2}{*}{$\begin{array}{l}\text { Cause of } \\
\text { Fatality }\end{array}$} & \multicolumn{3}{|c|}{ Under 16 Years of Age } & \multicolumn{3}{|c|}{16 to 19 Years of Age } \\
\hline & Frequency & Rate $^{a}$ & Str. Err. & Frequency & Rate $^{a}$ & Std. Err. \\
\hline Machine & 137 & 2.5 & 0.033 & 34 & 1.6 & 0.027 \\
\hline Motor vehicle & 96 & 1.8 & 0.023 & 25 & 1.2 & 0.020 \\
\hline Drowning & 76 & 1.4 & 0.018 & 36 & 1.7 & 0.028 \\
\hline Suicide & 14 & 0.3 & 0.003 & 41 & 1.9 & 0.032 \\
\hline Homicide & 8 & 0.2 & 0.002 & 30 & 1.4 & 0.024 \\
\hline Suffocation & $* * * *$ & $N / A$ & $N / A$ & $* * * *$ & $N / A$ & $N / A$ \\
\hline Animal & 27 & 0.5 & 0.007 & 3 & 0.1 & 0.002 \\
\hline Explosion & 17 & 0.3 & 0.004 & 13 & 0.6 & 0.010 \\
\hline $\begin{array}{l}\text { Struck by } \\
\text { falling object }\end{array}$ & 15 & 0.3 & 0.004 & 13 & 0.6 & 0.010 \\
\hline Electrocution & 10 & 0.2 & 0.002 & 6 & 0.3 & 0.005 \\
\hline Fall & 7 & 0.1 & 0.002 & 7 & 0.3 & 0.006 \\
\hline $\begin{array}{l}\text { Nature/ } \\
\text { environment }\end{array}$ & 6 & 0.1 & 0.001 & 5 & 0.2 & 0.004 \\
\hline Poisoning & 3 & 0.1 & 0.001 & 6 & 0.3 & 0.005 \\
\hline Air transport & 6 & 0.1 & 0.001 & 3 & 0.1 & 0.002 \\
\hline $\begin{array}{l}\text { Flying object/ } \\
\text { caught in }\end{array}$ & $* * * *$ & $N / A$ & $N / A$ & $* * * *$ & $N / A$ & $N / A$ \\
\hline Fire & $* * * *$ & $N / A$ & $N / A$ & $* * * *$ & $N / A$ & $N / A$ \\
\hline Unknown & $* * * *$ & $N / A$ & $N / A$ & $* * * *$ & $N / A$ & $N / A$ \\
\hline Total & 469 & 8.7 & 0.113 & 226 & 10.4 & 0.177 \\
\hline
\end{tabular}

**** Not reportable.

N/A Not Applicable.

Source: Death certificate data: years 1999 and 2000 exclude data from Delaware, Massachusetts, Michigan, Nebraska, New Jersey, New York, and Oregon; years 1995-2000 exclude New York City.

${ }^{a}$ Rate refers to annual number of fatalities per 100,000 youths under 20 years of age. 
the machine-related fatality rate for children under 5 years of age is 5.2 per 100,000 children. This is almost double the overall rate for the age group under $16(2.6$ per 100,000) and the rate for children 5 to 9 years of age $(2.8$ per 100,000$)$. The third highest fatality rate for youths 16 to 19 years of age is from machine-related causes, while the third highest rate for children and youths under 16 is from drowning. Although drowning is the third leading cause of death for youths under 16 , for children under 5 the fatality rate for drowning is 3.9 fatalities per 100,000 annually. As is found with regard to machinery, this rate for the youngest age group is much higher than the rate found in any other age group. Again, it appears that certain factors pose very similar hazards to youths on the farm, regardless of age group, but this hazard may take a different form. For example, exposure to the hazard of a motor vehicle may vary from an older child driving a car to a younger child being improperly restrained within the car. These data also show that within the two major age categories, there may be important variation by age indicating increased hazard to specific youths.

\section{Discussion}

Data from this study indicate that, in general, youths under 16 years of age and youths 16 to 19 years of age face similar overall risk of fatalities on farms. These data allow for a more robust determination of "on farm" fatalities to youths and children. The inclusion of all children less than 16 , and the inclusion of non-work related incidents, allows for examination of all risk factors to youths on the farm. The child playing near the running tractor faces risk of injury just as the youths driving the tractor while mowing the field, though the level of risk and circumstances may differ. By not accounting for the deaths of children under 16 years of age, or deaths of youths not classified as work-related, we are missing a large number of fatalities essentially caused by similar causes of death as those included in most previous occupational studies. However, this research supports the findings of authors such as Salmi et al. (1989), Pickett, Brison, and Hoey (1995), and the Centers for Disease Control and Prevention (CDC, 1999b) that indicate a varied nature of death dependent on age and the need for ageappropriate prevention strategies.

The fatality rates calculated with these data are also very similar to those found in other research. Rivara (1997) calculated an annual fatality rate of 8.0 deaths to youths under 20 years of age living on farms for the years 1990 to 1993. This is comparable to the rate found in this study of 9.3 fatalities per 100,000 youths on U.S. farms. In addition, Rivara (1997) found that the fatality rate for youths 16 to 19 years of age was 10.2 fatalities per 100,000 youths, while Castillo et al. (1999) found that 12.2 youths of this age were killed per 100,000 full-time-equivalents in 1992-1996. These rates are again similar to the rate of 10.4 fatalities per 100,000 youths age 16 to 19 living and working on U.S. farms. Although these studies are not directly comparable due to the differences in population, the findings are still similar. This similarity is most likely due to the overwhelming influence derived from the number of fatalities occurring to youths living on the farm, a population that is included in each of these rate calculations.

\subsection{Research needs}

This study provides evidence that further work to address the role of varied developmental stages within the under 16 years of age group is necessary. Although these data do not allow for in-depth study within each cause of death due to the relatively small number of fatalities within categories, the high fatality rates found for children under 5 with death caused by machinery and drowning indicate that the broad age category may mask relevant variations by specific age.

Physical size, attention to tasks, experience, and visibility have all been cited as potential factors in the increased risk to youths on farms (CDC, 1999a; Schulman et al., 1997). Given the difference between the rates by cause of death, it appears that children under 16 are likely to die as a result of their size, strength, and ability to assess the existence of danger. For example, these children are likely to be run over by tractors or killed by animals. In both instances, their proximity to the hazard and their size and strength are likely to be contributing factors. Among youths 16 to 19, causes of death may be related to underestimation of a known danger, such as the case with the fatalities caused by gunshot wounds (explosions).

With regard to suicide, Pampel and Williamson (2001) identify age, economic competition, lack of supervision, and reduced family cohesion as risk factors. These risk factors may be present on farms as opportunity for economic advancement declines within rural areas. However, the suicide rate found in this research of 1.1 annual fatalities per 100,000 farm youths aged 10-19 is lower than the overall suicide rate of 5.4 per 100,000 for the same age group in the general population (for the year 1992; CDC, 1995). In addition, for the years 1985 through 1994, Pampel and Williamson (2001) find the suicide rate for males age 15 to 24 to be 19.7 per 100,000 and approximately 5 per 100,000 for females within the same age group. Thus, suicide among youths on the farm appears to be less prevalent than youth suicide in general. However, as it is the predominant cause of death for older youths, the psychological needs of youths on farms must be recognized and addressed. Additionally, the availability and efficacy of rural mental-health services for youths should be addressed in future research.

\subsection{Limitations}

Although this study used death certificate data for any fatality occurring on, or related to, the farm, there are 
issues related to the quality of the data that need to be discussed. For example, as noted by Conroy and Sciortino (1997, p. 274) "occupational location is more difficult to identify when the workplace is an agricultural environment that has multiple uses." In other words, we cannot be sure that the determination of "injury at work?" on the death certificate is accurate. Although it is clear that many of the fatalities in this study are recreational (e.g., hunting incidents), there are a number of cases that appear to be workrelated but are not coded as such. These data indicate a relatively low-number of work-related fatalities overall; however, it must be noted that this variable may not truly indicate whether or not the victim was working, or whether the death occurred as a result of work being performed by others. For example, as noted previously, a child fatally struck by a tractor while playing will not be deemed a work-related fatality, regardless of whether or not the tractor operator was working. Additionally, there is no indication whether or not the victim was doing normal household chores, which may be considered work. These factors may result in an under-estimation of work-related fatalities on farms. In addition, an assumption is also made that each fatality in these data is related to the farm. This may not be the case, as has been discussed with regard to homicides. Motor-vehicle incidents, airplane crashes, and homicides are all events in which the decedent may die on farm property but have no relationship to the farm or farm family. Finally, these data do not include all fatalities to farm family members, which occur off the farm property. For example, motor-vehicle fatalities occurring on the highway are not included. In each case, the limitations of the data make accurate rate calculation difficult.

Finally, with regard to rate calculation, there is error associated with these rates based upon the utilization of only one year's data to determine population. Again, the 1998 CAIS was used to estimate the number of youths, by age, on U.S. farms. Utilization of this number requires an assumption that the actual number of youths on these farms does not vary drastically within the six years covered by the study. As there is no accurate information available to assess the validity of this assumption, this must be recognized as a limitation of this study.

\section{Summary}

Youths must be made aware of the dangers they face, particularly when participating in recreational activities specific to rural or farm environments. Parents must be made aware of the dangers their younger children face simply by being in proximity to various hazards. As noted by Pickett et al. (1995), younger children are injured or killed when they are: (a) left unsupervised during busy times, (b) left in proximity to unguarded or moving machinery, (c) accompany workers near moving farm machinery, or (d) are asked to perform a task inappropriate to their age. The implication of these findings is that education of farm families as a whole is important.

For the protection of younger children, restrictive play areas should be established and maintained (Lee, Gallagher, Marlenga, \& Hard, 2002; CDC, 1999b). Each member of the farm family should be aware that, especially during working hours, young children should not be allowed to play outside these areas. In addition, limiting access to hazards through actions such as placing a fence around a body of water could limit hazard exposure for the youngest members of the farm family. Other possible solutions may include increased availability or utilization of childcare during the busy seasons (CDC, 1999b). For the older youths, increased supervision and training may lead to a greater understanding of the hazards associated with farming and decrease risky behaviors.

Although it is difficult to effectively study the risk to younger children on the farm, this study shows that in many situations younger children face hazards similar to, or greater than, that of older children. Given the nature of farming, particularly on the family farm, many of these fatalities result from hazard exposure unique to the farm environment. Therefore, it is incumbent upon researchers addressing issues of agricultural work-related injuries and fatalities to include all potential victims in their analysis. Only through careful and complete analysis will we be capable of addressing risk in a comprehensive and effective manner.

\section{References}

Adekoya, N., \& Pratt, S. (2001). Fatal unintentional farm injuries among persons less than 20 years of age in the United States: Geographic profiles. DHHS (NIOSH) Publication No. 2001-131. Morgantown, WV: Department of Health and Human Services, Centers for Disease Control and Prevention, National Institute for Occupational Safety and Health.

Castillo, D., Adekoya, N., \& Myers, J. R. (1999). Fatal work-related injuries in the agricultural production and services sectors among youths in the United States. Journal of Agromedicine, 6(3), 27-41.

Centers for Disease Control and Prevention [CDC]. (1999a). Childhood work-related agricultural fatalities-Minnesota, 1994-1997. Morbidity and Mortality Weekly Report, 48(16), 332-335.

Centers for Disease Control and Prevention [CDC]. (1999b). Deaths among children aged $\leq 5$ years from farm machinery runoversIowa, Kentucky, and Wisconsin, 1995-1998, and United States, 1990-1995. Morbidity and Mortality Weekly Report, 48(28), $605-608$.

Centers for Disease Control and Prevention [CDC]. (1995). Suicide among children, adolescents, and young adults-United States 1980-1992. Morbidity and Mortality Weekly Report, 44(15), 289-291.

Conroy, C., \& Sciortino, S. (1997). Describing patterns of occupational agricultural deaths: The effect of case definition. Journal of Safety Research, 28(4), 273-281.

Derstine, B. (1996, December 1-3). Job-related fatalities involving youths, 1992-1995. Compensation and Working Conditions, December 1-3.

Field, W., \& Tormoehlen, R. (1982). Analysis of fatal and non-fatal farm accidents involving children. Presented at the American Society of Agricultural Engineers, Palmer House, Chicago, Illinois, December $14-17$. 
Janicak, C. (2000). Occupational fatalities to workers age 65 and older involving tractors in the crops production agriculture industry. Journal of Safety Research, 31(3), 143-148.

Lee, B., Gallagher, S., Marlenga, B., \& Hard, D. (2002). Childhood agricultural injury prevention: Progress report and updated national action plan from the 2001 summit. Marshfield, WI: Marshfield Clinic.

Myers, J., \& Adekoya, N. (2001). Fatal on-farm injuries among youths 16 to 19 years of age: 1982-1994. Journal of Agricultural Safety and Health, 7(2), 101-112.

Myers, J., \& Hendricks, K. (2001). Injuries Among Youth on Farms in the United States, 1998. DHHS (NIOSH) Publication No. 2001-154. Morgantown, WV: Department of Health and Human Services, Centers for Disease Control and Prevention, National Institute for Occupational Safety and Health.

Pampel, F., \& Williamson, J. (2001). Age patterns of suicide and homicide mortality rates in high-income nations. Social Forces, 80(1), $251-282$.

Pickett, W., Brison, R., \& Hoey, J. (1995). Fatal and hospitalized agricultural machinery injuries to children in Ontario, Canada. Injury Prevention, 1, 97-102.

Richardson, D., Loomis, D., Wolf, S., \& Gregory, E. (1997). Fatal agricultural injuries in North Carolina by race and occupation, 1977-1991. American Journal of Industrial Medicine, 31, 452-458.

Rivara, F. (1997). Fatal and non-fatal farm injuries to children and adolescents in the United States, 1990-1993. Injury Prevention, 3, $190-194$.

Rivara, F. (1985). Fatal and non-fatal farm injuries to children and adolescents in the United States. Pediatrics, 76(4), 567-573.

Salmi, L., Weiss, H., Peterson, P., Spengler, R., Sattin, R., \& Anderson, H. (1989). Fatal farm injuries among young children. Pediatrics, 83(2), $267-271$.
Schulman, M., Evensen, C., Runyan, C., Cohen, L., \& Dunn, K. (1997). Farm work is dangerous for teens: agricultural hazards and injuries among North Carolina teens. The Journal of Rural Health, 13(4), $295-305$.

Tormoehlen, R. (1986). Fatal farm accidents occurring to Wisconsin children, 1970 - 1984. Presented at the American Society of Agricultural Engineers, Hyatt Regency, Chicago, Illinois, December 16-19.

World Health Organization [WHO]. (1977). International classification of diseases: Manual on the international statistical classification of diseases, injuries, and causes of death. 9th revision. Geneva, Switzerland: Author.

Dr. Michael Goldcamp is an epidemiologist with the Centers for Disease Control and Prevention, National Institute for Occupational Safety and Health. He joined the staff in 2001 after previous work in cancer control and immunizations. Dr. Goldcamp is a graduate of West Virginia University (Ph.D., 2000) and the University of Cincinnati (B.A., 1991). He is currently working in the area of agricultural injury surveillance.

Kitty Hendricks joined the Centers for Disease Control and Prevention, National Institute for Occupational Safety and Health as a research epidemiologist in 1997. Ms. Hendricks received her master of arts from West Virginia University in 1995. Her past research includes work on white-collar crime, child labor, and agricultural injuries to youth.

John Myers has over fifteen years experience as a statistician with the Centers for Disease Control and Prevention, National Institute for Occupational Safety and Health. His work has primarily focused upon surveillance of agriculture related injuries. Mr. Myers holds a master of science degree from West Virginia University and has completed all but the dissertation requirements for his doctorate. 